\title{
Temperature management after hypothermic circulatory arrest
}

\author{
Joseph S. Coselli, MD
}

Scott A. LeMaire, MD

See related article on page 724 .

From the Division of Cardiothoracic Surgery, Baylor College of Medicine and The Methodist DeBakey Heart Center, Houston, Tex.

Received for publication Dec 27, 2001; accepted for publication Jan 9, 2002.

Address for reprints: Joseph S. Coselli, MD, 6560 Fannin St, Suite 1100, Houston, TX 77030 (E-mail: jcoselli@bcm.tmc.edu).

J Thorac Cardiovasc Surg 2002;123:621-3

Copyright (๑) 2002 by The American Association for Thoracic Surgery

0022-5223/2002 \$35.00+0 $\quad \mathbf{1 2 / 1 / 1 2 2 7 0 9}$

doi:10.1067/mtc.2002.122709

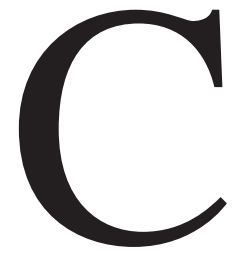

erebral protection during the surgical treatment of complex aortic disease, primarily involving the transverse aortic arch, continues to be a major clinical challenge for cardiac surgeons. Profound hypothermic circulatory arrest (HCA) remains a mainstay for brain protection during such operations because it is simple and has been efficacious in broad clinical use. However, despite its extensive use and inherent simplicity, HCA has important limitations. Most notably, the protective effect of profound hypothermia decreases as the circulatory arrest time increases. In a review of a series of 656 patients undergoing aortic surgery with HCA reported by Svensson and associates, ${ }^{1}$ the stroke and mortality rates increased significantly after 40 minutes and 65 minutes of HCA, respectively.

Considerable difference of opinion exists as to how to overcome the inherent time constraints of HCA. Although most of the debates center on the selection of different perfusion techniques (ie, retrograde and antegrade cerebral perfusion) and potential pharmacologic adjuncts, the ideal temperature management strategy also remains unresolved. Whereas previous reports have focused on temperature management before and during $\mathrm{HCA},{ }^{2-5}$ recent studies have given more attention to post-HCA temperature management, especially during the rewarming phase. ${ }^{6,7}$

\section{Postoperative Hypothermia: A New Area of Investigation}

In this issue of the Journal, Romsi and his coworkers ${ }^{8}$ have extended the study of temperature management beyond the operating room by evaluating prolonged postoperative mild hypothermia in a porcine HCA model. After 75 minutes of HCA, 10 pigs underwent immediate rewarming to $37^{\circ} \mathrm{C}$ while 10 others were rewarmed to only $32^{\circ} \mathrm{C}$ and were kept at that temperature for 14 hours. In all animals, postoperative temperature was regulated with a heat-exchange mattress, heating lamps, and ice packs. Several beneficial effects of postoperative hypothermia were initially observed in the treatment group, including increased mixed venous oxygen saturation, decreased oxygen extraction and consumption rates, reduced brain lactate and glutamate levels, and reduced intracranial pressures. Ultimately, however, each of these effects was "negatively reversed" by the time of extubation on the morning after the operation. Furthermore, the animals that underwent postoperative hypothermia exhibited strong trends toward higher mortality and poorer behavioral scores. Despite the fact that these differences did not reach statistical significance, multiple physiologic differences between the groups did reach statistical significance and supported the authors' conclusion that the use of prolonged hypothermia was detrimental. For example, in the prolonged hypothermia group, serum concentrations of creatine kinase-BB were significantly increased, leukocyte and neutrophil counts were significantly decreased, and electroencephalographic burst recovery was significantly lower.

This unique study represents an important first step in investigating postoperative hypothermia as a potential adjunct for cerebral protection. By contrasting the initial beneficial effects of mild hypothermia with the detrimental effects after prolonged hypothermia, the study clearly illustrates that the real challenge is to determine how to optimize the postoperative period of hypothermia as to depth and duration, thereby maximizing its benefits while minimizing its adverse effects. As the authors 
state, additional "studies are required to elucidate the efficacy of short-term mild hypothermia after HCA."

Two important limitations of the study warrant discussion. As the first chronic experimental model of its type (ie, porcine HCA followed by postoperative mild hypothermia), the study is unavoidably underpowered. This is demonstrable in their evaluation of the results, whereupon the clear trends toward higher mortality and poorer behavioral scores in the prolonged hypothermia group did not achieve statistical significance. This problem, however, is entirely understandable, because predicting expected complication rates without preliminary data is often not feasible. When viewed as the first of a series of experiments, we submit that this is but a minor limitation.

More important, the authors' current experimental model has limited applicability to the clinical setting of adult aortic arch surgery. Cerebral injury after aortic arch repair under HCA is clearly multifactorial and is caused by hypoperfusion, reperfusion, and embolization. Although the first two factors are well addressed by the model, the third is not. The typical patient undergoing arch repair is subject to a potentially large embolic load, including gaseous, atheromatous, and lipid emboli. In contrast, the experimental model uses closed heart surgery in young pigs without diffuse atherosclerosis or arch disease and would be expected to generate few, if any, cerebral emboli. Some of the benefits of hypothermia may be in reducing the size and extent of brain injury after embolic stroke. Therefore, a lack of benefit in this animal model may not translate into a lack of benefit in the clinical setting. Future studies should incorporate the delivery of a standard embolic load to address this issue. ${ }^{9}$

\section{Current Clinical Implications}

Although never specifically studied in detail, the use of a period of postoperative mild hypothermia after HCA is not without clinical precedence. For example, Hagl and colleagues ${ }^{7}$ from Mount Sinai recently reiterated their preference for rewarming gradually and discontinuing rewarming once a core temperature of $32^{\circ} \mathrm{C}$ to $33^{\circ} \mathrm{C}$ has been reached. Although not identified as a specific variable in their evaluation of 717 patients surviving ascending aorta-aortic arch operations with HCA, this rewarming strategy would be expected to result in at least a brief period (perhaps 2-6 hours) of mild postoperative hypothermia. The low incidence of transient stroke $(3.3 \%)$ and permanent stroke $(5.7 \%)$ in their series raises an unanswered question: did the consistent presence of postoperative hypothermia contribute to the excellent clinical results? Future clinical studies focusing on this variable will begin to provide the answer.

Given the importance of temperature management in patients subjected to HCA, the issue of where to measure temperature must be addressed. ${ }^{10,11}$ During cardiac surgery, the temperature of the brain is the critical, yet unknowable, variable. From a practical standpoint, the location that best reflects brain temperature is the jugular venous bulb. The temperature of the perfusate in the arterial inflow line also closely reflects brain temperature after only a few minutes of rewarming. Tympanic, esophageal, and nasopharyngeal temperatures are satisfactory guides, although they generally lag behind jugular bulb temperature. Both bladder and rectal temperatures are very poor indicators of brain temperature and should probably be ignored in this setting.

Although we are far from being able to make clinical recommendations regarding the use of post-HCA hypothermia, there is accumulating evidence supporting the strict avoidance of hyperthermia. ${ }^{12-14}$ In the setting of ischemia, hyperthermia causes acceleration of necrosis and may result in a larger area of infarction and a poorer outcome. The following guidelines comprise an aggressive strategy to avoid hyperthermia after HCA:

1. Use jugular bulb, nasopharyngeal, or tympanic temperature measurements to guide temperature management.

2. Regarding rewarming on cardiopulmonary bypass:

- Begin rewarming early and maintain the rewarming rate at less that $0.5^{\circ} \mathrm{C} / \mathrm{min}$.

- If possible, set the heat exchanger at or below $38^{\circ} \mathrm{C}$.

- Avoid perfusate and patient temperatures above $37^{\circ} \mathrm{C}$.

- Maintain the gradient between the perfusate and patient temperatures below $10^{\circ} \mathrm{C}$.

- Stop rewarming when patient temperature reaches $36.5^{\circ} \mathrm{C}$.

3. Using this approach, patients will often arrive in the intensive care unit with temperatures near $34^{\circ} \mathrm{C}$ to $35^{\circ} \mathrm{C}$ due to the "afterdrop" that inevitably follows cardiopulmonary bypass. Use warm air blankets to continue slow rewarming in the intensive care unit while avoiding patient temperatures above $37^{\circ} \mathrm{C}$.

4. Finally, during the early postoperative period, treat even mild fever $\left(>37.8^{\circ} \mathrm{C}\right)$ aggressively with antipyretics, especially in patients with neurologic deficits. We acknowledge that this strategy must be carefully balanced against the detrimental effects of hypothermia on coagulation and cardiac function. ${ }^{15,16}$ As always, the approach must be tailored to fit each individual patient's situation. In the meantime, we eagerly await further information regarding the potential benefits of actively using postoperative hypothermia.

\section{References}

1. Svensson LG, Crawford ES, Hess KR, Coselli JS, Raskin S, Shenaq $\mathrm{SA}$, et al. Deep hypothermia with circulatory arrest: determinants of stroke and early mortality in 656 patients. J Thorac Cardiovasc Surg. 1993;106:19-31.

2. Coselli JS, Crawford ES, Beall AC Jr, Mizrahi EM, Hess KR, Patel VM. Determination of brain temperatures for safe circulatory arrest during cardiovascular operation. Ann Thorac Surg. 1988;45:638-42. 
3. Guerit JM, Verhelst R, Rubay J, el Khoury G, Noirhomme P, Baele P, et al. The use of somatosensory evoked potentials to determine the optimal degree of hypothermia during circulatory arrest. J Card Surg. 1994;9:596-603.

4. Stecker MM, Cheung AT, Pochettino A, Kent GP, Patterson T, Weiss SJ, et al. Deep hypothermic circulatory arrest. I. Effects of cooling on electroencephalogram and evoked potentials. Ann Thorac Surg. 2001; 71:14-21.

5. Stecker MM, Cheung AT, Pochettino A, Kent GP, Patterson T, Weiss SJ, et al. Deep hypothermic circulatory arrest. II. Changes in electroencephalogram and evoked potentials during rewarming. Ann Thorac Surg. 2001;71:22-8.

6. Ehrlich MP, McCullough J, Wolfe D, Zhang N, Shiang H, Weisz D, et al. Cerebral effects of cold reperfusion after hypothermic circulatory arrest. J Thorac Cardiovasc Surg. 2001;121:923-31.

7. Hagl C, Ergin MA, Galla JD, Lansman SL, McCullough JN, Spielvoge $\mathrm{D}$, et al. Neurologic outcome after ascending aorta-aortic arch operations: effect of brain protection technique in high-risk patients. J Thorac Cardiovasc Surg. 2001;121:1107-21.

8. Romsi P, Heikkinen J, Biancari, F, Pokela M, Rimpiläinen J, Vainionpää $\mathrm{V}$, et al. Prolonged mild hypothermia after experimental hypothermic circulatory arrest in a chronic porcine model. J Thorac Cardiovasc Surg. 2002;123:624-34.
9. Stump DA, Jones TJ, Brown WR, Deal DD, Hammon JW, Moody D. The volume of embolic cerebral ischemic lesions is less during hypothermic cardiopulmonary bypass. Ann Thorac Surg. 1999;68:1463.

10. Stone JG, Young WL, Smith CR, Solomon RA, Wald A, Ostapkovich $\mathrm{N}$, et al. Do standard monitoring sites reflect true brain temperature when profound hypothermia is rapidly induced and reversed? Anesthesiology. 1995;82:344-51.

11. Marino MR, Cheng WP, Romagnoli A, Walding D, Nussmeier N. Temperature bias: jugular bulb venous temperature versus conventional sites. Ann Thorac Surg. 2000;70:1792.

12. Dietrich WD, Busto R, Valdes I, Loor Y. Effects of normothermic versus mild hyperthermic forebrain ischemia in rats. Stroke. 1990;21:1318-25.

13. Shum-Tim D, Nagashima M, Shinoka T, Bucerius J, Nollert G, Lidov HG, et al. Postischemic hyperthermia exacerbates neurologic injury after deep hypothermic circulatory arrest. $J$ Thorac Cardiovasc Surg. 1998;116:780-92.

14. Cook DJ. Cerebral hyperthermia and cardiac surgery: consequences and prevention. Semin Thorac Cardiovasc Surg. 2001;13:176-83.

15. Poli de Figueiredo LF, Coselli JS. Individual strategies of hemostasis for thoracic aortic surgery. J Card Surg. 1997;12:222-8.

16. Wilde JT. Hematologic consequences of profound hypothermic circulatory arrest and aortic dissection. J Card Surg. 1997;12:201-6. 